\title{
Effect of Pelvic Floor Descent on Posterior Pelvic Floor Disorders in Women with Obstructed Defecation Syndrome
}

\author{
Akira Tsunoda*, Tomoko Takahashi and Hiroshi Kusanagi \\ Department of Gastroenterological Surgery, Kameda Medical Center, Japan \\ *Corresponding Author: Akira Tsunoda, Department of Gastroenterological Surgery, \\ Kameda Medical Center, Japan.
}

Received: August 27, 2020

Published: September 30, 2020

(C) All rights are reserved by Akira Tsunoda., et al.

\begin{abstract}
Background: The relation between age, parity, and posterior pelvic floor disorders involving obstructed defecation syndrome (ODS) is a matter of controversy. This study aimed to determine the effect of pelvic floor descent (PFD) on the prevalence of posterior pelvic floor disorders in women with ODS.

Methods: Data for women with ODS, collected in a prospective pelvic floor database, and were assessed retrospectively. Data on demographic variables and defecography were analyzed. PFD during defecation was estimated by the degree of the anorectal junction in relation to the inferior margin of the ischial tuberosity.

Results: Of 334 women with ODS, the most frequently detected defecographic abnormalities were rectal intussusception (58\%) and rectocele (45\%). Regression analysis showed that the presence of rectocele and enterocele was more common in women with increased PFD. A higher incidence of rectocele and enterocele was found in women with excessive PFD ( $\geqq 30 \mathrm{~mm})$ than those without excessive PFD [58\% (68/118) vs. 37\% (77/209), P < 0.0001; 23\% (27/118) vs. 14\% (29/209), P = 0.038, respectively]. Increasing size of rectocele was significantly associated with increasing PFD. There were no significant differences in the prevalence of various posterior pelvic floor disorders between nulliparous and parous women.

Conclusions: The prevalence of both rectocele and enterocele increased significantly with increasing PFD in women with ODS, but the incidence of rectal intussusception showed no such relationship.
\end{abstract}

Keywords: Defecography; Pelvic Floor Descent; Rectocele; Rectal Intussusception; Enterocele

\section{Introduction}

Disorders of posterior pelvic floor are relatively common. They are frequently found in elderly female patients and are caused by morphologic and functional abnormalities due to changes in musculoaponeurotic support of the pelvic floor. Previous studies on the pelvic floor disorders have mainly focused on incontinence, and obstetric injury is strongly associated with the prevalence of fecal incontinence [1,2]. However, the relation between age, vaginal delivery, and posterior pelvic floor disorders involving obstructed defecation syndrome (ODS) is a matter of controversy [3-5]. The influence of aging or vaginal delivery on such disorders has been described in the previous studies $[3,6,7]$, but others have failed to identify the associations between childbirth and such disorders $[4,8]$.

Pelvic floor descent (PFD) was first described by Parks., et al. [9]. Excessive PFD indicates injury to the innervation of the pelvic floor [10]. We previously evaluated PFD in women without ODS using defecography and found that PFD on straining was more prevalent in parous women than nulliparous [11]. Although increased PFD has been also found in constipated patients, the relationships between the PFD and various anatomical abnormalities causing ODS such as rectocele, rectal intussusception or enterocele remains unclear $[12,13]$. 


\section{Aim of the Study}

The aim of this study was to determine the effect of PFD on the prevalence of posterior pelvic floor disorders as seen on defecography in women with ODS using multivariate analyses.

\section{Methods}

Patients seen in the proctology clinic with symptoms of rectal evacuatory disorder underwent defecography as a part of the investigation protocol. Between February 2010 and December 2019, 902 patients underwent defecography and data for these patients were prospectively entered into a pelvic floor database. Of those, male patients $(\mathrm{n}=262)$, or patients with external rectal prolapse $(n=131)$, fecal incontinence (FI) alone $(n=119)$, mucus discharge alone $(n=12)$ and other symptoms $(n=44)$ were excluded. The remaining 334 female patients with ODS were included in this study. Symptoms of ODS include incomplete evacuation, straining, digitation, sensation of incomplete evacuation and repetitive visits to the toilet. The Constipation Scoring System (CSS) score was used to quantify constipation on a scale of 0-30 points, with a higher score indicating worse constipation14). Patients were stratified in subgroups by parity to evaluate the prevalence of defecographic abnormalities.

This study was approved by the Ethical Committee of Kameda Medical Center (approved number, 19-176). Information of the study was made public, and patients were ensured that they could withdraw consent. However, no patient or their relatives subsequently refused to participate in the study.

\section{Defecography}

A standardized defecography technique was used in this study. The small bowel was opacified with a mixture containing $100 \mathrm{~mL}$ barium sulfate $(100 \% \mathrm{w} / \mathrm{w})$ and $10 \mathrm{~mL}$ Urografin $(60 \% \mathrm{w} / \mathrm{w})$, ingested $2 \mathrm{~h}$ prior to the procedure. Proctograms were evaluated using the criteria proposed by Shorvon., et al. [15]. Briefly, rectal intussusception is a circumferential descent of the entire thickness of the rectal wall, which might extent into the anal canal but not through the anal verge. A rectocele greater than $2 \mathrm{~cm}$ in diameter was regarded as abnormal. The size was calculated in the standard fashion in the anterior-posterior dimension by measuring the distance between the most ventral part of the anterior rectal wall and an extrapolated line indicating the expected position of the rectal wall [16]. PFD during defecation was estimated by the degree of the anorectal junction in relation to the inferior margin of the ischial tuberosity. Excessive PFD was defined as a descent of the anorectal junction $3 \mathrm{~cm}$ or more below the inferior margin of the ischial tuberosity. Enterocele was diagnosed when the extension of the loop of the bowel was located between the vagina and rectum. Mucosal prolapse is a thin prolapse starting 3 to $4 \mathrm{~cm}$ above the anal verge and passing through the anal verge. Pelvic floor dyssynergia was reported when the contour of the puborectalis muscle increased and/or the anorectal angle decreased at straining. Inadequate defecatory propulsion was reported when inadequate propulsive force was seen with or without the increased anorectal angle at straining. Images from defecography were analyzed by one of the authors (T. T.), who is experienced in the evaluation and was blinded at that time to the symptomatology of the individual patients.

\section{Statistical analysis}

Statistical analysis was performed using SPSS version 11.0 (SPSS Inc., Chicago, IL, USA). Continuous variables are expressed as median (range). Univariate associations were analyzed using the Mann-Whitney U-test or Pearson's correlation analysis for continuous variables and the chi-square or Fisher's exact test for categorical variables. Stepwise multivariate regression analysis was used to establish which variables best predicted the presence of anatomical abnormality. In the regression analysis, the presence of rectocele, rectal intussusception, or enterocele was selected as the dependent variable, respectively. Independent variables included age, parity, PFD, and the presence of other anatomical abnormalities. A value of $\mathrm{P}<0.05$ was taken as significant for all tests except for the stepwise multiple regression, where variables were entered at a P -value of $\leqq 0.01$ to reduce the risk of type I errors.

\section{Results}

The median age was 68 years (range, 22 - 95 years). Sixty-eight (20\%) women were nulliparous and $266(80 \%)$ had undergone one or more vaginal deliveries (median: 2; range 1 - 5). Forty-three women (13\%) had undergone a hysterectomy. Two hundred and twenty women (66\%) had OD alone, while 114 (34\%) had OD and FI. The median CSS score was 12 (6 - 30). The median PFD measured in 327 women was 25 ( -7 to 64 ) $\mathrm{mm}$, and excessive PFD was found in $36 \%$ (118/327).

Table 1 shows the prevalence of various defecographic abnormalities. The most frequently detected abnormalities were rectal intussusception and rectocele irrespective of the additional findings on defecography and their frequency was 58\% (194/334) and $45 \%$ (149/334), respectively. 


\begin{tabular}{|l|c|}
\hline Rectal intussusception (RI) alone & $103(30.8)$ \\
Rectocele (RC) alone & $63(18.9)$ \\
RI+RC & $56(16.8)$ \\
RI+enterocele (EC) & $17(5.1)$ \\
RI+RC+EC & $16(4.8)$ \\
RC+EC & $14(4.2)$ \\
EC alone & $9(2.7)$ \\
RI+mucosal prolapse & $2(0.6)$ \\
Inappropriate defecatory propulsion & $12(3.6)$ \\
Pelvic floor dyssynergia & $3(0.9)$ \\
\hline Parenthesis, percentage & \\
\hline
\end{tabular}

Table 1: Prevalence of defecographic abnormalities in female patients with obstructed defecation syndrome $(\mathrm{n}=334)$.

\section{Role of PFD}

The prevalence of defecographic abnormalities by PFD $<<30$ mm versus $\geqq 30 \mathrm{~mm}$ ) are shown in table 2 . Excessive PFD was significantly associated with the increased incidence of rectocele and enterocele, respectively. There were no significant differences in age, parity, or CSS score between the groups.

\section{Role of parity}

The prevalence of defecographic abnormalities by parity are shown in table 3 . There were no significant differences in the incidence of various defecographic abnormalities between nulliparous and parous women. Nulliparous women were significantly younger than parous women. PFD was not significantly different between nulliparous and parous women. CSS scores in nulliparous women were significantly higher than those in parous women.

\begin{tabular}{|c|c|c|c|}
\hline & \multicolumn{2}{|c|}{ Pelvic floor descent } & \multirow{2}{*}{$\mathbf{P}$} \\
\hline & $<30 \mathrm{~mm}(\mathrm{n}=209)$ & $30 \mathrm{~mm}(\mathrm{n}=118)$ & \\
\hline Rectal intussusception & $128(61 \%)$ & $63(53 \%)$ & 0.17 \\
\hline Rectocele & $77(37 \%)$ & $68(58 \%)$ & $<0.0001$ \\
\hline Enterocele & $29(14 \%)$ & $27(23 \%)$ & 0.04 \\
\hline Inappropriate defecatory propulsion & $10(5 \%)$ & $2(2 \%)$ & 0.22 \\
\hline Pelvic floor dyssynergia & $3(196)$ & $0(0 \%)$ & 0.56 \\
\hline Age (years) & $71(22-96)$ & $67(29-90)$ & 0.09 \\
\hline Nulliparae & $46(22 \%)$ & $22(19 \%)$ & 0.47 \\
\hline Previous hysterectomy & $29(14 \%)$ & $13(11 \%)$ & 0.46 \\
\hline CSS score & $12(6-30)$ & $13(5-21)$ & 0.09 \\
\hline
\end{tabular}

Table 2: Prevalence of defecographic abnormalities by pelvic floor descent $(n=327)$.

\begin{tabular}{|l|c|c|c|}
\hline \multirow{2}{*}{} & \multicolumn{2}{|c|}{ Parity } & \multirow{2}{*}{ P } \\
\cline { 2 - 4 } & Nulharous (n = 68) & Vaginal parous (n = 266) & \\
\hline Rectal intussusception & $38(56 \%)$ & $156(59 \%)$ & 0.68 \\
\hline Rectocele & $32(47 \%)$ & $117(44 \%)$ & 0.65 \\
\hline Enterocele & $9(13 \%)$ & $47(18 \%)$ & 0.38 \\
\hline Inappropriate defecatory propulsion & $2(3 \%)$ & $10(4 \%)$ & 1.00 \\
\hline Pelvic floor dyssynergia & $2(3 \%)$ & $1(0.4 \%)$ & 0.11 \\
\hline Pelvic floor descent (mm) & $24(-6-60)$ & $25(-4-64)$ & 0.31 \\
\hline Age (years) & $57(22-92)$ & $70(30-95)$ & $<0.0001$ \\
\hline Previous hysterectomy & $5(7 \%)$ & $38(14 \%)$ & 0.16 \\
\hline CSS score & $14(5-30)$ & $12(6-21)$ & 0.005 \\
\hline
\end{tabular}

Table 3: Prevalence of defecographic abnormalities by parity. 
Pearson's correlation coefficients and regression analysis

Presence of rectocele

The correlation between the presence of a rectocele, demographic findings, and morphologic parameters are shown in table 4. Younger age, increasing PFD, and the absence of rectal intussusception were significantly associated with the presence of rectocele. The results of the stepwise multiple regression analysis are shown in table 8. Younger age and increasing PFD were significantly associated with the presence of rectocele.

\begin{tabular}{|l|c|c|}
\hline & Coefficients & P \\
\hline Age (years) & -0.37 & $<0.0001$ \\
\hline Pelvic floor descent (mm) & 0.32 & $<0.0001$ \\
\hline Rectal intussusception (no,yes) & -0.18 & 0.001 \\
\hline Enterocele (no,yes) & 0.08 & 0.14 \\
\hline Previous hysterectomy (no,yes) & 0.03 & 0.55 \\
\hline Parity (no,yes) & -0.03 & 0.65 \\
\hline
\end{tabular}

Table 4: Pearson's correlation coefficients between the presence of rectocele and variables.

Size of rectocele $(n=149)$

The median size of rectocele was 30 (21-59) mm. The correlation between the size of the rectocele, demographic, and morphologic variables are shown in table 5. Increasing PFD, age, and the presence of enterocele were significantly associated with the size of the rectocele. The results of multivariate analysis showed that increasing PFD and younger age were significantly associated with increasing size of rectocele (Table 8).

\begin{tabular}{|l|c|c|}
\hline & Coefficients & P \\
\hline Pelvic floor descent (mm) & 0.32 & $<0.0001$ \\
\hline Age (years) & -0.24 & 0.004 \\
\hline Enterocele (no, yes) & 0.20 & 0.02 \\
\hline Rectal intussusception (no, yes) & -0.13 & 0.13 \\
\hline CSS score & 0.11 & 0.21 \\
\hline Previous hysterectomy (no, yes) & -0.04 & 0.66 \\
\hline Parity (no, yes) & -0.04 & 0.62 \\
\hline
\end{tabular}

Table 5: Pearson's correlation coefficients between the size of rectocele and variables $(n=149)$.

\section{Presence of rectal intussusception}

The correlation between the presence of rectal intussusception, demographic, and morphologic variables are shown in table 6. Older age and the absence of rectocele were significantly associated with the presence of rectal intussusception. The results of multi- variate analysis showed that older age was significantly associated with the presence of rectal intussusception (Table 8).

\section{Presence of enterocele}

The prevalence of enterocele was $17 \%$ (56/334). More than three-quarters $(43 / 56)$ of patients with EC had undergone hysterectomy. The correlation between the presence of enterocele, demographic, and morphologic variables are shown in table 7. Increasing PFD and previous hysterectomy were significantly associated with the presence of enterocele. The results of the multivariate analysis showed that previous hysterectomy and increasing PFD were significantly associated with the presence of enterocele (Table 8).

\begin{tabular}{|l|c|c|}
\hline & Coefficients & P \\
\hline Age (years) & 0.21 & $<0.0001$ \\
\hline Rectocele (no, yes) & -0.18 & 0.001 \\
\hline Pelvic floor descent (mm) & -0.09 & 0.11 \\
\hline Previous hysterectomy (no, yes) & 0.02 & 0.68 \\
\hline Parity (no, yes) & 0.02 & 0.68 \\
\hline Enterocele (no, yes) & 0.01 & 0.89 \\
\hline
\end{tabular}

Table 6: Pearson's correlation coefficients between the presence of rectal intussusception and variables.

\begin{tabular}{|l|c|c|}
\hline & Coefficients & P \\
\hline Previous hysterectomy (no, yes) & 0.31 & $<0.0001$ \\
\hline Pelvic floor descent (mm) & 0.16 & 0.004 \\
\hline Rectocele (no, yes) & 0.08 & 0.14 \\
\hline Age (years) & 0.08 & 0.14 \\
\hline Parity (no, yes) & 0.05 & 0.38 \\
\hline Rectal intussusception (no, yes) & 0.01 & 0.89 \\
\hline
\end{tabular}

Table 7: Pearson's correlation coefficients between the presence of enterocele and variables.

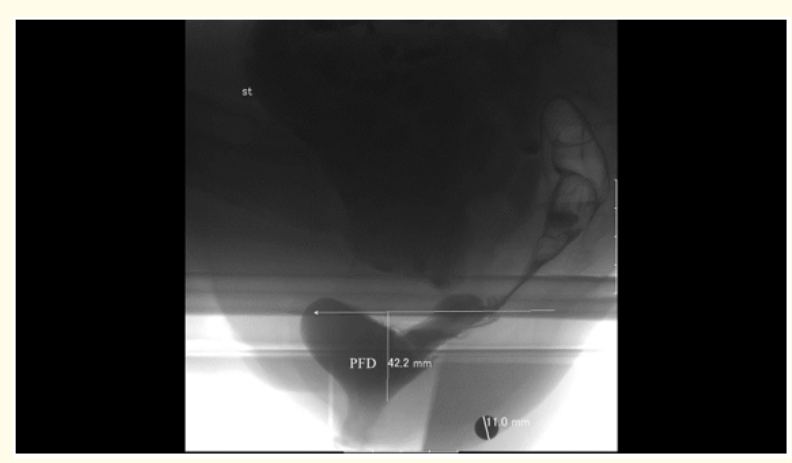

Figure 1: PFD, pelvic floor descent.

PFD was estimated by the degree of the anorectal junction in relation to the inferior margin of the ischial tuberosity during defecation. 
Effect of Pelvic Floor Descent on Posterior Pelvic Floor Disorders in Women with Obstructed Defecation Syndrome

40

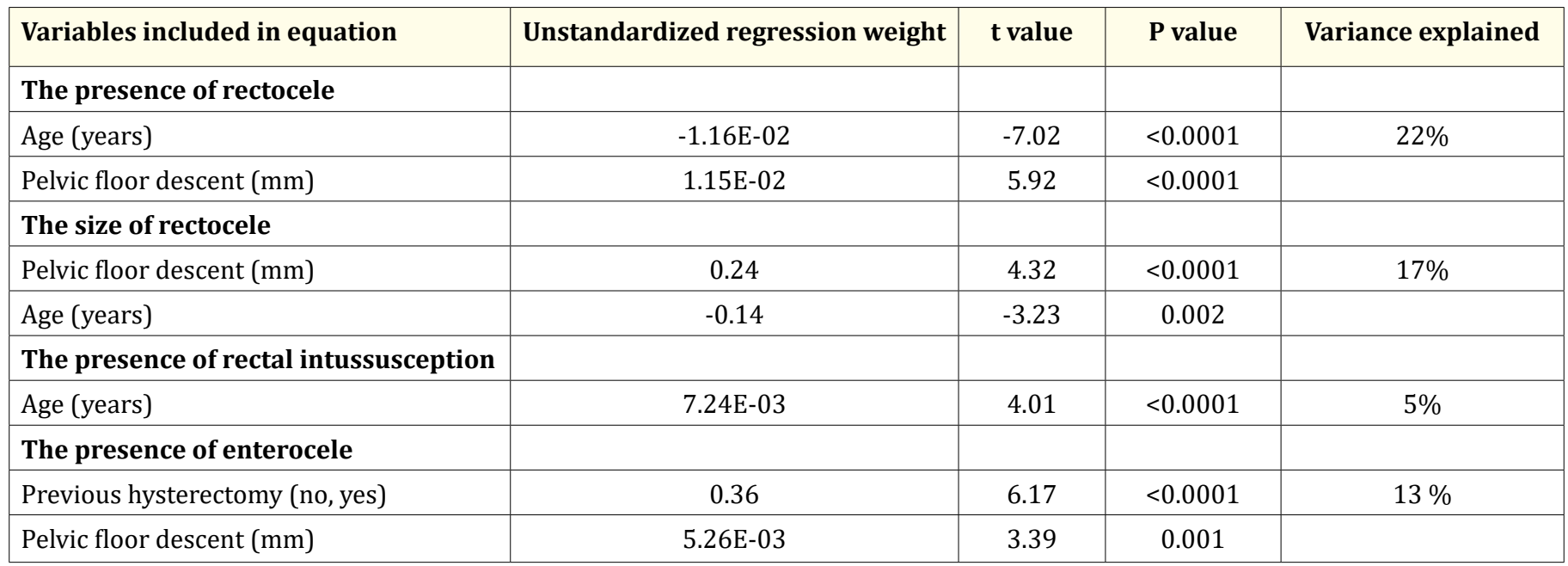

Table 8: Multiple regression.

\section{Discussion}

This study demonstrated that the prevalence of either rectocele or enterocele increased significantly with increasing PFD in women with ODS. Increasing rectocele size was also significantly associated with increasing PFD.

Our results support the view that vaginal delivery had no significant influence on the prevalence of ODS-related posterior pelvic floor disorders [4,5]. However, results vary between studies due to differences in population profile, study designs, techniques and imaging method performed during evaluation [3-5,17]. Kepenekci., et al. [3] estimated the prevalence of pelvic floor disorders among the general population of women by a questionnaire and found that childbirth and age to be associated with the development of both anterior and posterior pelvic floor disorders. Karasick., et al. [6] asked women who underwent defecography to provide information regarding obstetric history and pelvic surgery and found that trauma from childbirth or hysterectomy contributed to the development of defecation disorders. Murad-Regadas., et al. [7] evaluated the women presenting with ODS using 3D anorectal ultrasonography to assess the posterior pelvic floor disorders and found that delivery mode and parity were not correlated with the prevalence of rectocele, rectal intussusception and pelvic floor dyssynergia.

This study included 334 female patients presenting with ODS, with a median CSS score of 12 . The patients were evaluated using defecography to assess the prevalence of posterior pelvic floor disorders using multivariate analyses. Historically, defecography has placed an important role in the diagnosis of anatomical and func- tional abnormalities of the pelvic floor [18]. Magnetic resonance imaging and anorectal ultrasonography have limitations; both techniques are hindered by patient positioning (supine) because this position is non-physiologic and defecation in this system imposes practical difficulties and can lead to under-diagnosis of pelvic floor disorders $[19,20]$. Although the usefulness of the images acquired using dynamic magnetic resonance defecography with patient sitting in an open-magnet unit has been reported, this technique has not gained popularity because of the limited availability [21].

The major advantage of defecography consists in the fact that it provides a near physiologic evaluation of evacuation, allowing examination of the anatomy and function while the patient is in a position similar to the one in which the daily maneuvers that generate symptoms are performed [22]. This method is valuable in determining the maximum evacuation of the rectum, which allows for measuring not only the size of rectocele but also the physiologic extent of PFD. Rectal intussusception can be diagnosed at the end of evacuation stage, which is difficult to obtain in supine position [23].

Rectocele was common in women with increased PFD in this study, supporting the results of previous studies [12,13]. Excessive PFD was observed more than one-third of our patients. One explanation for this correlation might be chronic straining during defecation in women with rectocele, which is considered an etiologic factor of increased PFD. Conversely, chronic straining effort in women with constipation may cause fascial tears or detachment of the rectovaginal septum from the perineal body, which causes 
PFD. This has been described as possible factor attributing to the formation of rectocele [24]. It is uncertain why the presence of rectocele was more common in younger women. Although perineal trauma after childbirth was reported as a causing mechanism for rectocele formation [25], rectoceles have been described in nulliparous women in a few studies [17,25]. Diets., et al. [17] presumed that women are born with pre-existing defects of fascia that grow larger with time until they become evident on imaging or clinically. This may be possible explanation for the correlation between the presence of RC and younger age in this study. It is understandable that the size of rectocele became greater with increasing PFD, because the base of rectocele is likely to correlate with its depth, but the reason why younger women had a larger rectocele is uncertain. Carter., et al. [26] failed to find a significant correlation between the size of rectocele and age or parity.

The presence of rectal intussusception was more common in older women in this study, supporting the results of the previous study [8]. Hawskin., et al. [27] assessed 147 patients with OD who underwent defecography and showed that the patients with rectal intussusception were significantly older than those without rectal intussusception.

The incidence of enterocele was $17 \%$ in this study, similar to the incidence $(19 \%)$ reported in a review of 2,816 proctographies of patients with defecation disorders [28]. A previous history of hysterectomy predisposed women with ODS to have an enterocele in this study, supporting the results of the previous studies [28,29]. Hysterectomy may lead to a possible iatrogenic disruption of vaginal supportive tissue, which causes a change in vaginal axis or loss of continuing of fibrous connective tissue [30]. The possible causal relationship between the presence of enterocele and increasing PFD might be chronic straining effort in women with constipation. Chronic straining may cause not only deep Douglas pouch, but also pudendal neuropathy by stretching the nerve, which may lead to the development of increased PFD $[9,10]$.

Our study has certain limitations. This was a retrospective study of prospectively collected data. The symptoms of constipation or its severity may be affected by different factors apart from anatomical abnormalities such as health status and physical limitations. The study population comes from a single tertiary care center, and our findings may not be generalizable to all patients with posterior pelvic floor disorders causing ODS.

\section{Conclusion}

In conclusion, this study demonstrated that the prevalence of either rectocele or enterocele increased significantly with increasing PFD in women with ODS, but not the incidence of rectal intussusception. In women with ODS, vaginal delivery had no impact on the prevalence of posterior pelvic floor disorders, when assessed by defecography. To further determine the role of PFD on such disorders, prospective studies based on clinical and radiological tests are required.

\section{Acknowledgements}

The authors thank Yuko Tsunoda for her assistance with the statistical analysis.

\section{Conflict of Interest}

The authors declare that there are no conflicts of interest.

\section{Bibliography}

1. Snooks SJ., et al. "Effect of vaginal delivery on the pelvic floor: a 5-year follow-up". British Journal of Surgery 77 (1990): 13581360.

2. Sultan AH., et al. "Anal-sphincter disruption during vaginal delivery". New England Journal of Medicine 329 (1993): 19051911.

3. Kepenekci I., et al. "Prevalence of pelvic floor disorders in the female population and the impact of age, mode of delivery, and parity". Diseases of the Colon and Rectum 54 (2011): 85-94.

4. Murad-Regadas S., et al. "Defecographic pelvic floor abnormalities in constipated patients: does mode of delivery matter?" Techniques in Coloproctology 13 (2009): 279-283.

5. Soares FA., et al. "Role of age, bowel function and parity on anorectocele pathogenesis according to cinedefecography and anal manometry evaluation". Colorectal Disease 11 (2009): 947-950.

6. Karasick S., et al. "The role of parity and hysterectomy on the development of pelvic floor abnormalities revealed by defecography". American Journal of Roentgenology 169 (1997): 1555-1558.

7. Murad-Regadas SM., et al. "The influence of age on posterior pelvic floor dysfunction in women with obstructed defecation syndrome". Techniques in Coloproctology 16 (2012): 227-232. 
8. Murad-Regadas SM., et al. "Influence of age, mode of delivery and parity on the prevalence of posterior pelvic floor dysfunctions". Arquivos de Gastroenterologia 48 (2011): 265-269.

9. Parks AG., et al. "The syndrome of the descending perineum". Proceedings of the Royal Society of Medicine 59 (1966): 477482.

10. Bartolo DC., et al. "The relationship between perineal descent and denervation of the puborectalis in continent patients". International Journal of Colorectal Disease 1 (1986): 91-95.

11. Tsunoda A., et al. "The effect of vaginal delivery on the pelvic floor". Surgery Today 29 (1999): 1243-1247

12. Mellgren A., et al. "Defecography. Results of investigations in 2,816 patients". Diseases of the Colon and Rectum 37 (1994): 1133-1141.

13. Yoshioka K., et al. "Physiologic and anatomic assessment of patients with rectocele". Diseases of the Colon and Rectum 34 (1991): 704-708.

14. Agachan F., et al. "A constipation scoring system to simplify evaluation and management of constipated patients". Diseases of the Colon and Rectum 39 (1996): 681-685.

15. Shorvon PJ. et al. "Defecography in normal volunteers: results and implications". Gut 30 (1989): 1737-1749.

16. Bartram CI., et al. "Evacuation proctography: an investigation of rectal expulsion in 20 subjects without defecatory disturbance". Gastrointestinal Radiology 13 (1988): 72-80.

17. Dietz HP. et al. "The role of childbirth in the aetiology of rectocele". BJOG 113 (2006): 264-267.

18. Ekberg O., et al. "Defecography”. Radiology 155 (1985): 45-48

19. Vanbeckevoort D., et al. "Pelvic floor descent in females: comparative study of colpocystodefecography and dynamic fast MR imaging". Journal of Magnetic Resonance Imaging 9 (1999): 373-37.

20. Healy JC., et al. "Dynamic MR imaging compared with evacuation proctography when evaluating anorectal configuration and pelvic floor movement". American Journal of Roentgenology 169.3 (1997): 775-779.

21. Francesca I., et al. "MR Imaging in Diagnosis of Pelvic Floor Descent: Supine versus Sitting Position". Gastroenterology Research and Practice (2016): 6594152.
22. Maglinte DD., et al. "Dynamic imaging of posterior compartment pelvic floor dysfunction by evacuation proctography: techniques, indications, results and limitations". European Journal of Radiology 61 (2007): 454-461.

23. Ahmad AN., et al. "A review of functional pelvic floor imaging modalities and their effectiveness". Clinical Imaging 39 (2015): 559-565.

24. Segal JL., et al. "Evaluation and management of rectoceles". Current Opinion on Urology 12 (2002): 345-352.

25. Dietz HP., et al. "Prevalence of rectocele in young nulliparous women". Australian and New Zealand Journal of Obstetrics and Gynaecology 45 (2005): 391-394.

26. Carter D., et al. "Rectocele--does the size matter?" International Journal of Colorectal Disease 27 (2012): 975-980.

27. Hawkins AT., et al. "Impact of Rising Grades of Internal Rectal Intussusception on Fecal Continence and Symptoms of Constipation". Diseases of the Colon and Rectum 59 (2016): 54-61.

28. Mellgren A., et al. "Enterocele demonstrated by defaecography is associated with other pelvic floor disorders". International Journal of Colorectal Disease 9 (1994): 121-124.

29. Cruikshank SH. "Preventing vault prolapse and enterocele after vaginal hysterectomy". South Medical Journal 81 (1988): 594-596.

30. Chou Q., et al. "Clinical presentation of enterocele". Obstetrics and Gynecology 96 (2000): 599-603.

\section{Assets from publication with us}

- Prompt Acknowledgement after receiving the article

- Thorough Double blinded peer review

- Rapid Publication

- Issue of Publication Certificate

- High visibility of your Published work

Website: $\underline{w w w}$.actascientific.com/

Submit Article: www.actascientific.com/submission.php

Email us: editor@actascientific.com

Contact us: +919182824667 